\title{
The Design of Charging Controller in Wind-Photovoltaic Hybrid Power Generation System
}

\author{
Ting Wang \\ School of Computer Science, BaiCheng Normal University, Baicheng (137000), Jilin \\ loveting1982@163.com
}

\begin{abstract}
With the energy crisis and environmental degradation increasing, people are increasingly concerned about the development of environmental protection and new energy technologies. According to the output characteristics of solar photovoltaic batteries, this paper is designed to take a DC chopper as the main circuit of a photovoltaic battery, and on this basis, this paper studies control methods suitable for PV charging; according to the characteristic that the small wind power generation has a high requirement with the wind power generation, researchers use the lifting pressure circuit as the main circuit of a wind energy charger. Finally, this paper makes the software design for PV charging controllers and wind charging controllers.
\end{abstract}

Keywords-solar; wind power generation; wind-photovoltaic hybrid; DC chopper; the lifting pressure circuit

\section{INTRODUCTION}

Along with continuous improvement of the society, human hold increasingly more demands towards energy sources. At present, most energy sources are generated from nonrenewable resources such as coal, oil and natural gas with limited reserves, which produce plenty of greenhouse gases in the combustion process and bring a series of troubles to the environment. Renewable energy sources such as wind energy and solar energy are clean and pollution-free, which are distributed extensively, will be never used up and can settle insufficient energy sources and environmental troubles to a great extent. Meanwhile, they can also settle power utilization in some remote mountainous areas and islets without power grid. In recent years, wind-solar hybrid generating system will be a hotspot for studying and applying new energy sources as a flexible and stable energy supply system along with further reduction of cost, upgrading of industrial technology and supports from governmental finance and policy.

\section{OVERALl STRUCTURAL DESIGN OF THE SYSTEM}

The wind-photovoltaic hybrid power generation system consists of a wind turbine, a rectifier, a photovoltaic array, a DC/DC power converter, a battery, a super capacitor, an inverter, a controller, and a AC-DC multi-user load, etc., as shown in Figure 1. From the energy point of view, the entire system includes three segments, such as production, storage and consumption.

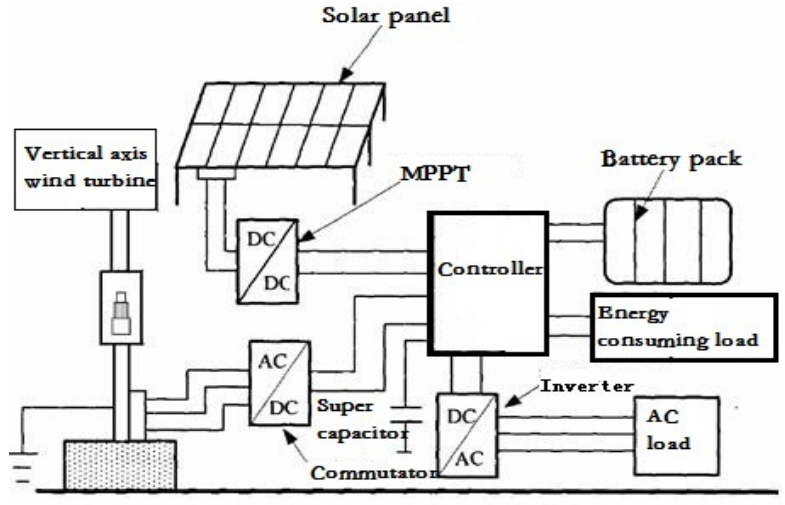

Figure 1. The overall configuration diagram of the system

\section{THE DESIGN OF THE CONTROL UNIT}

In the article, STC89S52 singlechip is the controller controlling the core design system as Figure 2, which converting unstable AC output from the wind driven generator and unstable DC output from the solar-cell panel into stable DC for storage battery and load; meanwhile, it controls the charge-discharge mode of storage battery and the working mode of the load, realizing scientific charge-discharge management of storage battery.

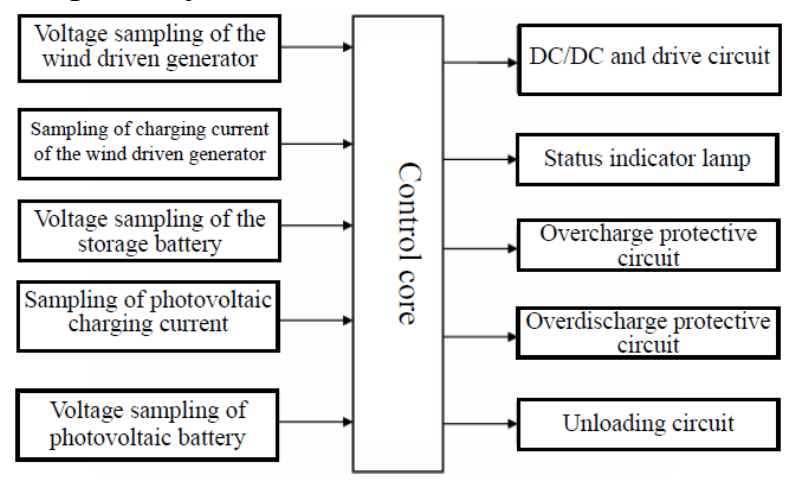

Figure 2. The structural diagram of the controller 


\section{The Design of the Solar Photovoltaic CHARGING CONTROLLER}

The structure diagram of a photovoltaic charger in wind-photovoltaic hybrid power generation system is shown in Figure 3, and it is mainly composed of solar photovoltaic batteries and photovoltaic charging controllers. The mission of the control circuit in PV charging controller is to detect the voltage at both ends of the input capacitance and the charging current of batteries in real time, and output the PWM signal of switch tubes through a voltage hysteresis control method. The control circuit uses a STC89S52 microcontroller as the main controller, the main function units of which includes a detection circuit and a switch driver circuit.

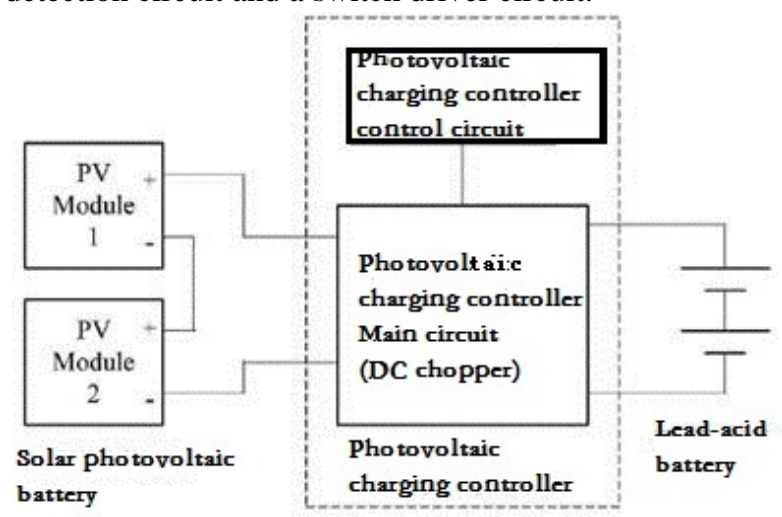

Figure 3. The structural diagram of the solar charging controller

\section{V.THE DESIgN OF THE WIND CHARgING CONTROLLER}

Unlike the main circuit of a photovoltaic charging controller adopts a DC chopper, the main circuit topology of a wind charging controllers uses a Buck lifting pressure circuit. The generator uses a three-phase synchronous AC generator with a permanent magnet and direct drive. The three-phase AC generated from the generator connects the main circuit (Buck converter) of the wind charging controller after passing the three-phase rectifier bridge. On one hand, the control circuit of the wind charging controller controls the PWM of the main circuit; on the other hand, it detects the rotational speed of the wind turbine in real time. When the wind speed reaches a fixed cut-off speed, the controller activates the automatic brake device to avoid the turbine being over-speed and damaged by excessive wind speed. The structural diagram of the wind charger in the wind-photovoltaic hybrid power generation system is shown in Figure 4.

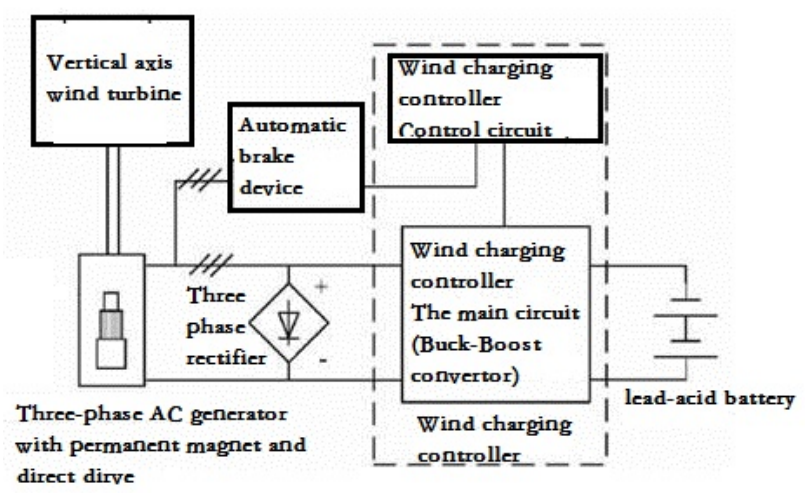

Figure 4. The structural diagram of the wind charging controller

\section{The SOFTWARE DESIGN OF THE SySTEM}

The charging controller takes the chip of microcontroller STC89S52 as the core of control, Figure 5 shows the program flow chart of the PV charging control circuit, and the Figure 6 shows the program flow chart of the wind charging control circuit.

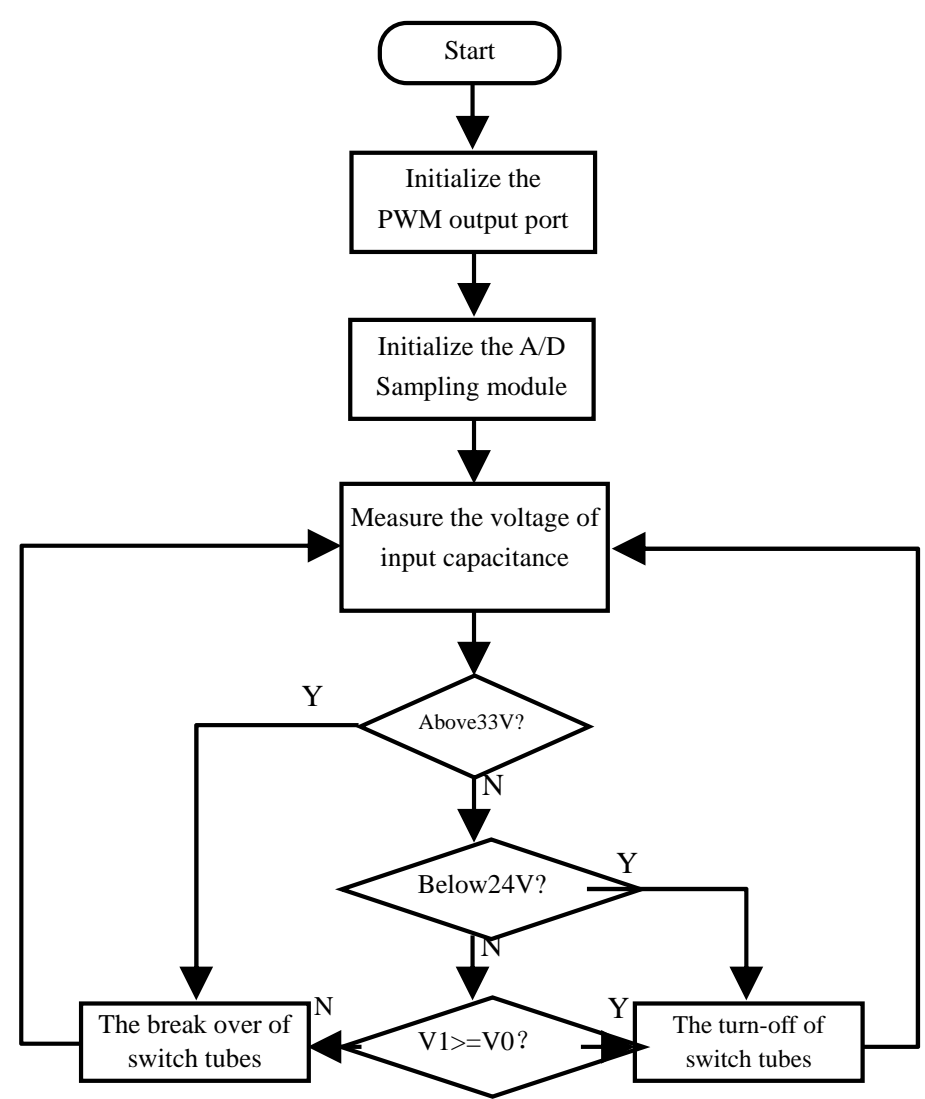

Figure 5. The program flow chart of the PV charging control circuit 


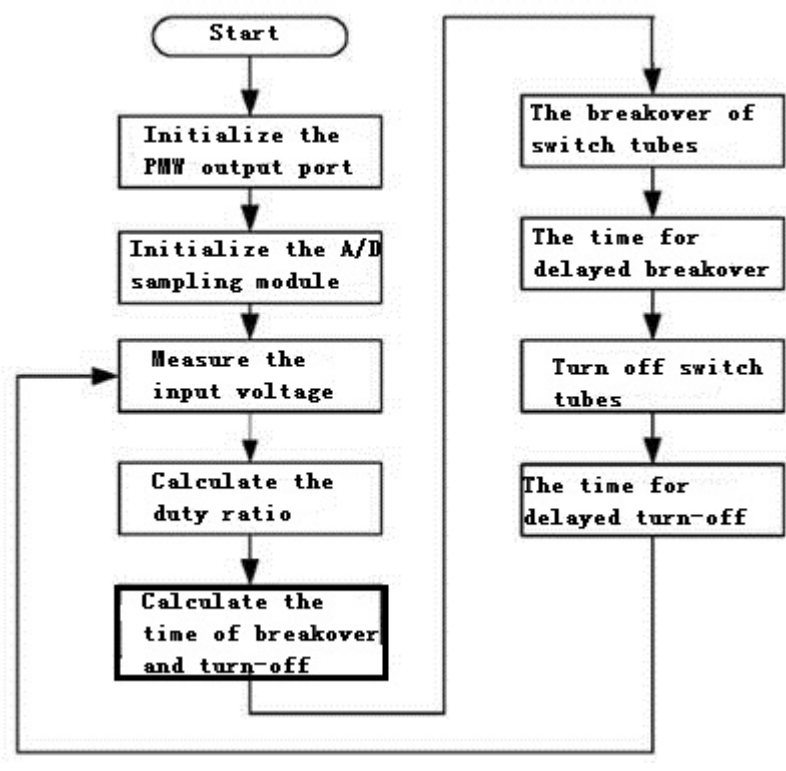

Figure 6 The program flow chart of the wind charging control circuit

\section{CONCLUSION}

This paper takes STC89S52 as the core of control to design the charging controller in a wind-photovoltaic hybrid power generation system. In the photovoltaic charging, the photovoltaic panels are compounded by two PV modules string together. This paper makes hardware and software design for the photovoltaic charging controller according to the output characteristics of photovoltaic batteries, and makes a prototype. In the wind energy charging, the generator uses a small three-phase permanent magnet synchronous generator, and the output AC connects the wind charging controller after passing a three-phase rectifier. This paper makes hardware and software design for the photovoltaic charging controller and makes a prototype, and the main circuit uses a Buck-Boost converter. In the control method, it constantly tests the rectified voltage and adjusts the duty cycle of switch tubes in the main circuit in real time according to the steady-state conditions of the Buck-Boost circuit, which allows the main circuit to work in boost state under breeze conditions when the input voltage is lower than the voltage of batteries, improving the breeze power generation performance in boost state; and allows the main circuit to work in depressurized state under strong wind conditions, improving the utilization efficiency of wind.

\section{REFERENCES}

[1] Ye Hangye. Control Technique of Wind Generating Set [M]. Beijing: China Machine Press, 2006

[2] Gong Jingyuan. Wind Farm Engineering Technique Manual [M]. Beijing: China Machine Press, 2004

[3] Wang Tao. Research on Integration Control of Small Wind-solar Hybrid Generating System [D].Hefei: Hefei University of Technology, 2009

[4] Cui Xiaoming. Research on Controller of Small Wind-solar Hybrid Generating System [D]. Inner Mongolia: Inner Mongol University of Technology, 2009

[5] Wang Changgui, Wang Sicheng. Practical Technique of Solar Photovoltaic Power Generation [M]. Beijing: Chemical Industry Press, 2005

[6] Zhang Yongyuan. Theory and Technique of Wind Power Generation [M].Taiwan: Industrial Technology Research Institute, 2007, 23 36.

[7] Hou Congling, Wu Jie and Li Jinpeng et al. Research on Charging Method of Lead-acid Storage Battery [J]. Power Supply Technology Application, 2004, 2: 118 121

[8] Mao Meiqin, Yu Shijie. Research on Simulating Modeling of Structure of Wind-light Hybrid Generating System [J]. Journal of System Simulation, 2003, 15(3): 361-364 